Article

\title{
Analysis of Association between Intake of Red Wine Polyphenols and Oxidative Stress Parameters in the Liver of Growing Male Rats
}

\author{
Aleksandra Kołota*(D), Dominika Głąbska ${ }^{\mathbb{D}}$, Michał Oczkowski $\mathbb{D}^{\mathbb{D}}$ and \\ Joanna Gromadzka-Ostrowska \\ Department of Dietetics, Institute of Human Nutrition Sciences, Warsaw University of Life \\ Sciences (SGGW-WULS), 159c Nowoursynowska Street, 02-776 Warsaw, Poland; \\ dominika_glabska@sggw.edu.pl (D.G.); michal_oczkowski@sggw.edu.pl (M.O.); \\ joanna_gromadzka_ostrowska@sggw.edu.pl (J.G.-O.) \\ *Correspondence: aleksandra_kolota@sggw.edu.pl; Tel.: +48-22-593-71-86
}

Received: 30 July 2020; Accepted: 11 September 2020; Published: 14 September 2020

\begin{abstract}
Red wine is a complex alcoholic beverage containing various substances, including those of a potential health-promoting properties, such as polyphenols, responsible for the sensory features of wine. Their potential positive influence is associated with possibility of antioxidative, anti-inflammatory, anticancer, immunomodulating, and antiallergenic effects, but at the same time, there is a possibility of their pro-oxidative effect. In spite of the fact that in adolescence alcohol may be highly damaging, as it may disturb the development, it is abused frequently. The aim of the study was to verify the association between red wine consumption as well as dietary polyphenol intake with wine and the oxidative stress parameters in the liver of growing male rats. The growing male Wistar rats were studied, while divided into three groups of six animals, receiving red wine in a solution characterized by $10 \%$ of ethanol content since 30th day of life, for two, four, and six weeks. The alcohol intake was controlled and the content of total phenolic compounds, selected phenolic acids (hydroxybenzoic acid, caffeic acid, p-coumaric acid, ferulic acid, and sinapic acid), total anthocyanidins and selected anthocyanins (cyanidin, cyanidin 3-glucoside, cyanidin 3-rutinoside, delphinidin, and pelargonidin) were assessed. At the same time, for the liver homogenates, the levels of Thiobarbituric Acid Reactive Substances (TBARS) and protein carbonyl groups were verified. The analysis revealed statistically significant influence of red wine intake, as well as of supply of phenolic acids (hydroxybenzoic acid, caffeic acid, p-coumaric acid, ferulic acid, and sinapic acid), and anthocyanins (cyanidin, cyanidin 3-glucoside, cyanidin 3-rutinoside, delphinidin, and pelargonidin) on TBARS and protein carbonyl groups level ( $\mathrm{R}>0.80 ; p<0.05)$, but the influence was stated only for the period of two weeks. The obtained results may suggest pro-oxidative effect of both ethanol and polyphenols for the liver of the growing male rats. At the same time, for the periods of four and six weeks, no influence on TBARS and protein carbonyl groups level was observed $(p>0.05)$, which may allow to suppose an adaptive mechanism of the growing organism while the ethanol and polyphenols exposition is prolonged. Further studies are required to confirm the mechanism of the pro-oxidative effect of polyphenols contained in red wine for the liver of growing organism.
\end{abstract}

Keywords: red wine; phenolic acids; anthocyanins; oxidative stress; adolescent; rats; liver

\section{Introduction}

The consequences of alcohol consumption in adolescence include alcohol abuse [1] and alcohol dependence in adulthood [2-4], social issues (e.g., aggression, violence, and accidents), and other 
health issues such as influence on the development and functioning of the brain [5,6], bones [7], endocrine system [8], and liver [9]. Hence, the period of adolescence is crucial for alcohol initiation and the subsequent risk [10]. The data obtained in 2015 from 34 European countries through the European School Survey Project on Alcohol and Other Drugs (ESPAD) survey [11] revealed that the preventive actions in this age group do not effectively change the behaviors, and alcohol consumption is still quite high. Such consumption of alcohol during adolescence may disturb the process of development, as it is associated with several crucial biological changes in a short time [12].

For adults, moderate consumption of red wine is one of the typical elements of Mediterranean diet [13], while low-to-moderate red wine consumption is attributed to the so-called Mediterranean alcohol consumption pattern [14]. The specific dietary patterns for alcoholic beverages, including consumption and preferences, are dependent on the country and are derived from cultural heritage of that country $[15,16]$. In several European countries, red wine is the major alcoholic beverage consumed, including southern and western Europe (e.g., Italy, Greece, Spain, Portugal, and France) and central and eastern Europe (Hungary, Bulgaria, Romania, and Slovenia) [17]. However, the Mediterranean alcohol consumption pattern is attributed to the population of adults alone [18], as the ESPAD data revealed that for adolescents, wine is the major alcoholic beverage consumed in other countries, including Ukraine, Moldova, and Georgia [11], and similar to that for adults, there are country-dependent differences in alcoholic beverage dietary patterns of adolescents [19].

Red wine, besides alcohol, contains a number of other components, including proteins, carbohydrates, fats, organic acids, aldehydes, esters, ketones, vitamins, minerals, and polyphenols; among these components, polyphenols are an important group of natural compounds, as their content in red wine is much higher than that in white wine [20]. The main polyphenols in red wine are flavonoids, which contribute to its sensory features and its health-promoting properties [21]. Flavonoids are classified into various groups, including flavanols, flavanones, anthocyanidins (such as delphinidin and pelargonidin), stilbenes (such as resveratrol), hydroxycinnamic acids, and phenolic acids (such as coumaric acid, caffeic acid, and ferulic acid) [22-24]. Flavonoids occurring in red wine exhibit various properties, including antioxidative, anti-inflammatory, anticancer, immunomodulating, and antiallergenic effects [25]. The antioxidative properties of flavonoids enable the prevention of lipid peroxidation and low-density lipoprotein oxidative changes [26]; thus, the antioxidants contained in red wine may reduce oxidative stress and its consequences [27].

The liver is a specific organ for alcohol consumption as ethanol is metabolized by the liver, it is especially prone to consequences of alcohol consumption [28]. At the same time, a crucial issue linked to alcohol consumption is not only the influence of ethanol on the liver but also the effect of antioxidative components that may act as pro-oxidants, stimulating free radical generation, and causing DNA damage [26]. As there are limited possibilities to study the influence of red wine consumption in adolescents on the oxidative stress parameters in the liver in human participants, the aim of the study was to verify the association between red wine consumption, as well as dietary polyphenol intake with wine and the oxidative stress parameters of lipid peroxidation and protein oxidation in the liver of growing male rats.

\section{Materials and Methods}

\subsection{Study Design}

The study was accepted by the Local Ethics Committee for Animal Experiments at the Warsaw University of Life Sciences, SGGW-WULS, Poland (for the study protocol: 21/2007 and for conducted analysis: 26/2007).

The study was conducted in a group of 18 male Wistar rats, that was homogenic, with an identical age of 20 days while beginning acclimatization and 30 days while beginning animal experiment, and with an initial body mass of $92.76 \pm 9.32$ at the age of 20 days, being obtained from the Mossakowski Medical Research Centre of the Polish Academy of Sciences (Warsaw, Poland). Since this moment 
rats were housed individually at constant room temperature $\left(23 \pm 2{ }^{\circ} \mathrm{C}\right)$, humidity of $50-55 \%$, in a 12-h light/12-h dark cycle and were provided ad libitum a standard laboratory diet (Labofeed $\mathrm{H}$, Morawski Animal Feed Manufacturer, Kcynia, Poland).

For animal model studies it is important if animals are housed individually or in a group, as both individual housing (due to social isolation) and housing in a group (due to social competition within the group, which is influenced by factors such as the size of groups, the group composition, space available, and the despotism of the dominant individual) may be a stressors [29]. This problem is especially important in the case of studies analyzing the influence of alcohol intake, as the alcohol intake may be influenced by a stress which is experienced by animal [30]. At the same time, for such studies, it is crucial to monitor carefully the individual alcohol intake, along with the decision to choose the model of individual housing, rather than housing in groups, as both options may influence the level of stress and resultant alcohol intake [31]. Such an approach was applied in the number of studies of various authors analyzing alcohol intake which housed their rats individually [32-35]. In such situations, in order to reduce the influence of isolation on a stress that is experienced by animal, the acclimatization period should be applied. Moreover, if rats are housed individually while being juvenile, this is the other factor which may reduce their stress [36]. Based on the experiences by other researchers, such model was applied in order to reduce the level of stress, as animals were housed individually while being juvenile, and the acclimatization period was applied. Moreover, during all the experimental procedures, as well as during acclimatization period, animals were in the same room and remained in olfactory, auditory, and visual contact with their conspecifics, which is the other aspect that may reduce their stress [37].

The scheme of the study is presented in Figure 1. Before the experiment, there was a period of acclimatization, when rats received dry red wine (Sophia Sakar, Cabernet Sauvignon, Domain Menada, Stara Zagora, and Bulgaria, $11 \%$ alc. vol.) diluted in tap water to increasing concentration of ethanol ( $2 \%, 4 \%, 6 \%, 8 \%$, and $10 \%$ (vol./vol.) ethanol solution), while the concentration was increased each second day.

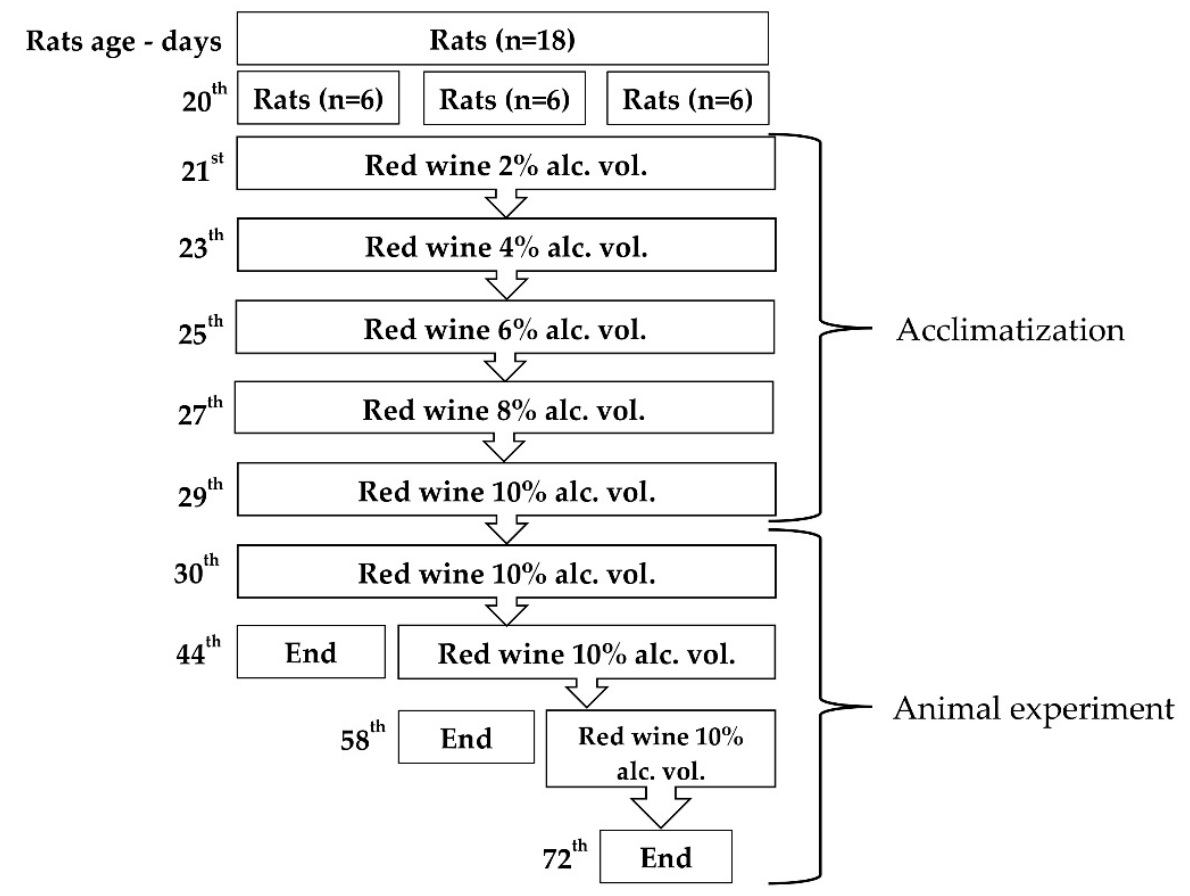

Figure 1. The scheme of the conducted study of the induced red wine consumption in the group of young male Wistar rats. 
After period of acclimatization, during the experimental period, rats received identical dry red wine (Sophia Sakar, Cabernet Sauvignon, Domain Menada, Stara Zagora, and Bulgaria, $11 \%$ alc. vol.) $10 \%$ (vol./vol.) ethanol solution, as in the last stage of acclimatization, as in the previously published studies [38,39]. The wine was chosen on the basis of its characteristics, with the aim to find the wine which is broadly available and relatively cheap, but also characterized by a simple flavor, which results from the fact that for adolescents abusing alcohol, a price is among the most important determinants of its consumption. In the review by Chaloupka [40], it was indicated that the majority of studies on price and youth drinking conclude that higher alcoholic beverage prices significantly reduce the probability, frequency, and level of drinking among youth, so in order to develop an accurate model of adolescents abusing alcohol, we tried to choose a wine with the highest possibility to be chosen in real market conditions.

Animals received the prepared solution ad libitum and no water during the dark cycle, that was applied according to the common procedure of inducing alcohol consumption in the animal model [41]. Animals were randomly divided into 3 groups ( 6 animals each), and the experiment duration was for them 2,4 , and 6 weeks.

\subsection{Analytical Methods and Measurements}

\subsubsection{Liver Homogenate Preparation}

After experimental period (after 2, 4, or 6 weeks, depending on the group), animals were sacrificed after overnight fasting, at the phase of deep anesthesia, by intraperitoneal thiopental administration (amount calculated as $120 \mathrm{mg} / \mathrm{kg}$ body weight). The rats were bled up (by cardiac puncture) and the livers were obtained as the study material; they were immediately excised, washed with ice-cold $0.9 \%$ physiological saline $(\mathrm{NaCl})$ solution, portioned, blotted dry, and frozen-stored at $-80{ }^{\circ} \mathrm{C}$. Afterwards, liver tissues were homogenized (homogenizer PRO 200, PRO Scientific Inc., Oxford, CT, USA) with nine volumes of ice-cold $50 \mathrm{mM}$ phosphate buffer characterized by $\mathrm{pH}$ of 7.4, containing 1M ethylenediaminetetraacetic acid (EDTA, Sigma-Aldrich, St. Louis, MO, USA). The obtained homogenates were centrifuged $\left(9000 \times g\right.$ for $20 \mathrm{~min}$ at $\left.4{ }^{\circ} \mathrm{C}\right)$ and the supernatant was pipetted into $1.5 \mathrm{~mL}$ Eppendorf tubes and, in order to reduce the bias associated with storage, it was frozen-stored at $-80{ }^{\circ} \mathrm{C}$ in aliquots without any thawing until analysis.

\subsubsection{Liver Homogenate Analysis}

The obtained samples of liver homogenates were used to assess the oxidative stress parameters-the levels of Thiobarbituric Acid Reactive Substances (TBARS) and protein carbonyl groups.

The level TBARS was measured in the obtained samples of liver homogenates using a spectrophotometric method according to the procedure by Ohkawa et al. [42].

The level of protein carbonyl groups was measured in the obtained samples of liver homogenates after additional preparation according to the method by Reznick and Packer [43], using a colorimetric method according to the procedure by Levine et al. [44].

\subsubsection{Red Wine Analysis}

During the experimental period, the intake of red wine solution was controlled daily, for each rat. Afterwards, the consumed amount of red wine was recalculated per ethanol intake, total phenolic compounds, selected phenolic acids (hydroxybenzoic acid, caffeic acid, p-coumaric acid, ferulic acid, and sinapic acid), total anthocyanidin, and selected anthocyanins (cyanidin, cyanidin 3-glucoside, cyanidin 3-rutinoside, delphinidin, and pelargonidin) were determined.

The total phenolic compounds were assessed with Folin-Ciocalteu reagent applied, using the procedure by Singleton and Rossi [45]. 
The selected phenolic acids (hydroxybenzoic acid, caffeic acid, p-coumaric acid, ferulic acid, and sinapic acid), and selected anthocyanins (cyanidin, cyanidin 3-glucoside, cyanidin 3-rutinoside, delphinidin, and pelargonidin) were assessed using a high performance liquid chromatography (HPLC) method according to the procedure by Häkkinen et al. [46]. The total anthocyanidins were calculated based on the content of cyanidin, cyanidin 3-glucoside, cyanidin 3-rutinoside, delphinidin, and pelargonidin.

\subsection{Statistical Analysis}

The distribution for assessed variables was verified using the W Shapiro-Wilk test. The results were presented as mean \pm standard deviation (SD). The one-way analysis of variance (ANOVA) with the Duncan's post hoc test were performed. The analysis of correlation was conducted while using the Pearson's correlation coefficient (due to normal distribution of data). Data were analyzed using the Statistica software version 13.1 (StatSoft Inc., Tulsa, OK, USA). The statistical significance was considered at $p<0.05$.

\section{Results}

The daily intake of red wine, ethanol, phenolic acids, and anthocyanins from wine, recalculated per $\mathrm{kg}$ of body weight, assessed for the studied rats during the experiment is presented in Table 1, while the daily intake of red wine, ethanol, phenolic acids, and anthocyanins from wine assessed for the studied rats during the experiment (without any recalculation) is presented in Table 2 . The daily red wine and ethanol intake ( $\mathrm{g} / \mathrm{kg}$ body weight) differed significantly and the lowest daily intakes were observed for the group attributed to a six weeks of the experiment. However, for daily intakes not recalculated to body weight, there were no differences observed, which indicates that the differences were associated with differences of body mass. Similarly, the daily total phenolic acids, caffeic acid, ferrulic acid, hydroxybenzoic acid, sinapic acid, p-coumaric acid, total anthocyanins, cyanidin, cyanidin 3-glucoside, cyanidin 3-rutinoside, delphinidin, and pelargonidin intake ( $\mathrm{mg} / \mathrm{kg}$ body weight) differed significantly and the lowest daily intakes were observed for the group attributed to six weeks of the experiment, but while not recalculated, there were no differences observed, confirming that differences were associated with differences of body mass. Only for pelargonidin were the differences still observed for the non-recalculated values. There was no significant between-group difference for daily red wine (g), ethanol intake (g) phenolic acids intake (mg), and anthocyanins intake (mg).

Body weight of rats and selected oxidative stress parameters levels in liver of male Wistar rats during the experiment are presented in Table 3. The final body weight and body weight gain (g) differed significantly between the studied groups, and the highest final body weight and body weight gain were observed for the group attributed to six weeks of the experiment.

Thiobarbituric acid-reactive substances and protein carbonyl group level in liver of male Wistar rats are presented in Table 3. The protein carbonyl group level in liver differed significantly and independently from the experiment duration; the highest final body weight and body weight gain were observed during four weeks of the experiment. 
Table 1. Daily intake of red wine, ethanol, phenolic acids, and anthocyanins from wine, recalculated per kg of body weight, assessed for the studied rats during the experiment.

\begin{tabular}{|c|c|c|c|c|c|c|c|}
\hline \multirow{2}{*}{ Parameter } & \multirow{2}{*}{$\begin{array}{c}2 \text { Weeks } \\
\text { Mean } \pm \text { SD }\end{array}$} & \multirow{2}{*}{$\begin{array}{c}4 \text { Weeks } \\
\text { Mean } \pm \text { SD }\end{array}$} & \multirow{2}{*}{$\begin{array}{c}6 \text { Weeks } \\
\text { Mean } \pm \text { SD }\end{array}$} & \multicolumn{4}{|c|}{$p$-Value } \\
\hline & & & & ANOVA & 2 vs. 4 & Duncan Test 2 vs. 6 & 4 vs. 6 \\
\hline Red wine intake (g/kg body weight) & $52.43 \pm 13.7^{\mathrm{a}}$ & $47.31 \pm 9.13^{\mathrm{a}, \mathrm{b}}$ & $35.43 \pm 5.89^{b}$ & $<0.05$ & NS & $<0.05$ & NS \\
\hline Ethanol intake ( $\mathrm{g} / \mathrm{kg}$ body weight) & $5.46 \pm 1.43^{\mathrm{a}}$ & $4.93 \pm 0.95 \mathrm{a}, \mathrm{b}$ & $3.69 \pm 0.61^{b}$ & $<0.05$ & NS & $<0.05$ & NS \\
\hline TPA (mg/kg body weight) & $0.78 \pm 0.20$ & $0.71 \pm 0.14$ & $0.53 \pm 0.09$ & $<0.05$ & NS & $<0.05$ & NS \\
\hline CA (mg/kg body weight) & $0.017 \pm 0.00^{\mathrm{a}}$ & $0.015 \pm 0.00^{\mathrm{a}, \mathrm{b}}$ & $0.011 \pm 0.00^{b}$ & $<0.05$ & NS & $<0.05$ & NS \\
\hline FA (mg/kg body weight) & $0.07 \pm 0.02^{\mathrm{a}}$ & $0.06 \pm 0.01 \mathrm{a}, \mathrm{b}$ & $0.04 \pm 0.01^{b}$ & $<0.05$ & NS & $<0.05$ & NS \\
\hline HBA (mg/kg body weight) & $0.54 \pm 0.14^{\mathrm{a}}$ & $0.49 \pm 0.09 \mathrm{a}, \mathrm{b}$ & $0.37 \pm 0.06^{b}$ & $<0.05$ & NS & $<0.05$ & NS \\
\hline $\mathrm{SA}$ (mg/kg body weight) & $0.009 \pm 0.00$ & $0.009 \pm 0.00$ & $0.006 \pm 0.00^{b}$ & $<0.05$ & NS & $<0.05$ & NS \\
\hline pCA (mg/kg body weight) & $0.15 \pm 0.04^{\mathrm{a}}$ & $0.13 \pm 0.03^{a, b}$ & $0.09 \pm 0.02 \mathrm{~b}$ & $<0.05$ & NS & $<0.05$ & NS \\
\hline TA (mg/kg body weight) & $3.29 \pm 0.98^{a}$ & $3.03 \pm 0.65^{\mathrm{a}}$ & $1.72 \pm 0.32^{b}$ & $<0.05$ & NS & $<0.05$ & $<0.01$ \\
\hline $\mathrm{C}$ (mg/kg body weight) & $0.07 \pm 0.02^{a}$ & $0.06 \pm 0.01^{\mathrm{a}, \mathrm{b}}$ & $0.04 \pm 0.01^{b}$ & $<0.05$ & NS & $<0.05$ & NS \\
\hline C3G (mg/kg body weight) & $0.39 \pm 0.10^{\mathrm{a}}$ & $0.35 \pm 0.07^{\mathrm{a}, \mathrm{b}}$ & $0.26 \pm 0.04^{b}$ & $<0.05$ & NS & $<0.05$ & NS \\
\hline C3R (mg/kg body weight) & $0.06 \pm 0.02^{a}$ & $0.05 \pm 0.01^{\mathrm{a}, \mathrm{b}}$ & $0.04 \pm 0.01^{b}$ & $<0.05$ & NS & $<0.05$ & NS \\
\hline $\mathrm{D}$ (mg/kg body weight) & $0.16 \pm 0.04^{\mathrm{a}}$ & $0.15 \pm 0.03^{a, b}$ & $0.11 \pm 0.02^{b}$ & $<0.05$ & NS & $<0.05$ & NS \\
\hline $\mathrm{P}$ (mg/kg body weight) & $2.62 \pm 0.81^{a}$ & $2.41 \pm 0.55^{\mathrm{a}}$ & $1.26 \pm 0.24^{b}$ & $<0.01$ & NS & $<0.01$ & $<0.01$ \\
\hline
\end{tabular}

$(\mathrm{a}, \mathrm{b})$ Different superscript letters indicate a significant difference between groups stratified by experiment duration (a vs. b, for $p \leq 0.05$; TPA—-total phenolic acids, CA—caffeic acid, FA-ferrulic acid, HBA - hydroxybenzoic acid, SA—sinapic acid, pCA-p-coumaric acid, TA-total anthocyanins, C-cyanidin, C3G-cyanidin 3-glucoside, C3R-cyanidin 3-rutinoside, D-delphinidin, $\mathrm{P}$ - pelargonidin, and NS-nonsignificant statistically. 
Table 2. Daily intake of red wine, ethanol, phenolic acids, and anthocyanins from wine assessed for the studied rats during the experiment.

\begin{tabular}{|c|c|c|c|c|c|c|c|}
\hline \multirow{2}{*}{ Parameter } & \multirow{2}{*}{$\begin{array}{c}2 \text { Weeks } \\
\text { Mean } \pm \text { SD }\end{array}$} & \multirow{2}{*}{$\begin{array}{c}4 \text { Weeks } \\
\text { Mean } \pm \text { SD }\end{array}$} & \multirow{2}{*}{$\begin{array}{c}6 \text { Weeks } \\
\text { Mean } \pm \text { SD }\end{array}$} & \multicolumn{4}{|c|}{$p$-Value } \\
\hline & & & & ANOVA & 2 vs. 4 & Duncan Test 2 vs. 6 & 4 vs. 6 \\
\hline Red wine intake (g) & $10.95 \pm 2.49$ & $9.67 \pm 2.16$ & $10.28 \pm 1.50$ & NS & NS & NS & NS \\
\hline Ethanol intake (g) & $1.09 \pm 0.25$ & $0.97 \pm 0.22$ & $1.03 \pm 0.15$ & NS & NS & NS & NS \\
\hline TPA (mg) & $0.16 \pm 0.04$ & $0.14 \pm 0.03$ & $0.15 \pm 0.02$ & NS & NS & NS & NS \\
\hline CA (mg) & $0.0003 \pm 0.0008$ & $0.003 \pm 0.001$ & $0.003 \pm 0.0005$ & NS & NS & NS & NS \\
\hline FA (mg) & $0.014 \pm 0.03$ & $0.012 \pm 0.0027$ & $0.013 \pm 0.001$ & NS & NS & NS & NS \\
\hline HBA (mg) & $0.114 \pm 0.025$ & $0.100 \pm 0.022$ & $0.107 \pm 0.02$ & NS & NS & NS & NS \\
\hline $\mathrm{SA}(\mathrm{mg})$ & $0.002 \pm 0.0004$ & $0.002 \pm 0.0004$ & $0.002 \pm 0.0003$ & NS & NS & NS & NS \\
\hline pCA (mg) & $0.030 \pm 0.007$ & $0.027 \pm 0.006$ & $0.028 \pm 0.004$ & NS & NS & NS & NS \\
\hline $\mathrm{TA}(\mathrm{mg})$ & $0.68 \pm 0.17$ & $0.61 \pm 0.12$ & $0.49 \pm 0.08$ & NS & NS & NS & NS \\
\hline C (mg) & $0.014 \pm 0.003$ & $0.012 \pm 0.003$ & $0.013 \pm 0.002$ & NS & NS & NS & NS \\
\hline C3G (mg) & $0.081 \pm 0.02$ & $0.072 \pm 0.02$ & $0.076 \pm 0.01$ & NS & NS & NS & NS \\
\hline C3R (mg) & $0.013 \pm 0.003$ & $0.011 \pm 0.002$ & $0.012 \pm 0.002$ & NS & NS & NS & NS \\
\hline $\mathrm{D}(\mathrm{mg})$ & $0.03 \pm 0.008$ & $0.03 \pm 0.01$ & $0.03 \pm 0.004$ & NS & NS & NS & NS \\
\hline $\mathrm{P}(\mathrm{mg})$ & $0.54 \pm 0.14^{\mathrm{a}}$ & $0.49 \pm 0.09^{a, b}$ & $0.37 \pm 0.06^{b}$ & $<0.05$ & NS & $<0.05$ & NS \\
\hline
\end{tabular}

$(\mathrm{a}, \mathrm{b})$ Different superscript letters indicate a significant difference between groups stratified by experiment duration (a vs. b), for $p \leq 0.05$. TPA—-total phenolic acids, CA- caffeic acid, FA-ferrulic acid, HBA—hydroxybenzoic acid, SA—sinapic acid, pCA—p-coumaric acid, TA— total anthocyanins, C—cyanidin, C3G-cyanidin 3-glucoside, C3R—cyanidin 3-rutinoside, $\mathrm{D}$-delphinidin, P-pelargonidin, and NS-nonsignificant statistically

Table 3. Body weight, diet intake, and selected oxidative stress parameters levels in liver of male Wistar rats assessed during the experiment.

\begin{tabular}{|c|c|c|c|c|c|c|c|}
\hline \multirow{2}{*}{ Parameter } & \multirow{2}{*}{$\begin{array}{c}2 \text { Weeks } \\
\text { Mean } \pm \text { SD }\end{array}$} & \multirow{2}{*}{$\begin{array}{c}4 \text { Weeks } \\
\text { Mean } \pm \text { SD }\end{array}$} & \multirow{2}{*}{$\begin{array}{c}6 \text { Weeks } \\
\text { Mean } \pm \text { SD }\end{array}$} & \multicolumn{4}{|c|}{$p$-Value } \\
\hline & & & & ANOVA & 2 vs. 4 & Duncan Test 2 vs. 6 & 4 vs. 6 \\
\hline Final body weight (g) & $211.18 \pm 19.4^{b}$ & $204.16 \pm 19.7^{b}$ & $290.77 \pm 7.2^{\mathrm{a}}$ & $<0.01$ & NS & $<0.01$ & $<0.01$ \\
\hline Body weight gain (g) & $118.25 \pm 11.6^{b}$ & $110.73 \pm 17.9^{b}$ & $198.85 \pm 8.9^{a}$ & $<0.01$ & NS & $<0.001$ & $<0.001$ \\
\hline Diet intake $(\mathrm{g} / \mathrm{d})$ & $15.06 \pm 1.15$ & $16.18 \pm 1.26$ & $16.12 \pm 1.09$ & NS & NS & NS & NS \\
\hline TBARS ( $\mu \mathrm{mol} / \mathrm{mg}$ protein) & $0.36 \pm 0.07$ & $0.41 \pm 0.09$ & $0.38 \pm 0.04$ & NS & NS & NS & NS \\
\hline PCG $(\mathrm{nmol} / \mathrm{mL})$ & $21.49 \pm 5.26^{\mathrm{a}}$ & $12.11 \pm 5.38^{b}$ & $26.71 \pm 8.82^{a}$ & $<0.01$ & $<0.05$ & $<0.001$ & NS \\
\hline
\end{tabular}

$(\mathrm{a}, \mathrm{b})$ Different superscript letters indicate a significant difference between groups stratified by experiment duration (a vs. b), for $p \leq 0.05$. TBARS—-thiobarbituric acid-reactive substances level, PCG—-protein carbonyl group level, and NS—nonsignificant statistically. 
Table 4. Analysis of correlation between intake of red wine, ethanol, phenolic acids, anthocyanins, thiobarbituric acid-reactive substances (TBARS), and protein carbonyl group level (PCG) in liver of the studied rats after two, four, and six weeks of experiment.

\begin{tabular}{|c|c|c|c|c|c|c|c|c|c|c|c|c|c|c|c|c|c|c|}
\hline \multirow{3}{*}{ Parameter } & \multicolumn{6}{|c|}{2 Weeks } & \multicolumn{6}{|c|}{4 Weeks } & \multicolumn{6}{|c|}{6 Weeks } \\
\hline & \multicolumn{2}{|c|}{ Red Wine Intake } & \multicolumn{2}{|c|}{ Ethanol Intake } & \multicolumn{2}{|c|}{ TBARS } & \multicolumn{2}{|c|}{ Red Wine Intake } & \multicolumn{2}{|c|}{ Ethanol Intake } & \multicolumn{2}{|c|}{ TBARS } & \multicolumn{2}{|c|}{ Red Wine Intake } & \multicolumn{2}{|c|}{ Ethanol Intake } & \multicolumn{2}{|c|}{ TBARS } \\
\hline & $p$ & $\mathbf{R}$ & $p$ & $\mathbf{R}$ & $p$ & $\mathbf{R}$ & $p$ & $\mathbf{R}$ & $p$ & $\mathbf{R}$ & $p$ & $\mathbf{R}$ & $p$ & $\mathbf{R}$ & $p$ & $\mathbf{R}$ & $p$ & $\mathrm{R}$ \\
\hline $\begin{array}{l}\text { Red wine } \\
\text { intake }\end{array}$ & \multicolumn{2}{|c|}{-} & $<0.05$ & 0.95 & \multicolumn{2}{|c|}{ NS } & \multicolumn{2}{|c|}{-} & $<0.05$ & 0.87 & \multicolumn{2}{|c|}{ NS } & \multicolumn{2}{|c|}{-} & $<0.001$ & 0.99 & \multicolumn{2}{|c|}{ NS } \\
\hline $\begin{array}{c}\text { Ethanol } \\
\text { intake }\end{array}$ & $<0.05$ & 0.95 & \multicolumn{2}{|c|}{-} & $<0.05$ & 0.87 & $<0.05$ & 0.87 & \multicolumn{2}{|c|}{ - } & \multicolumn{2}{|c|}{ NS } & $<0.001$ & 0.99 & \multicolumn{2}{|c|}{ - } & \multicolumn{2}{|c|}{ NS } \\
\hline TPA & $<0.05$ & 0.95 & \multicolumn{2}{|c|}{ NS } & $<0.05$ & 0.87 & $<0.05$ & 0.87 & \multicolumn{2}{|c|}{ NS } & & & $<0.05$ & 0.95 & \multicolumn{2}{|c|}{ NS } & & \\
\hline $\mathrm{CA}$ & $<0.05$ & 0.95 & \multicolumn{2}{|c|}{ NS } & $<0.05$ & 0.87 & $<0.05$ & 0.87 & \multicolumn{2}{|c|}{ NS } & & & $<0.001$ & 0.99 & \multicolumn{2}{|c|}{ NS } & & \\
\hline FA & $<0.05$ & 0.95 & & & $<0.05$ & 0.87 & $<0.05$ & 0.87 & & & & & $<0.001$ & 0.99 & $\mathrm{~N}$ & & & \\
\hline HBA & $<0.05$ & 0.95 & & & $<0.05$ & 0.87 & $<0.05$ & 0.87 & & & & & $<0.001$ & 0.99 & $\mathrm{~N}$ & & & \\
\hline $\mathrm{SA}$ & $<0.05$ & 0.95 & & & $<0.05$ & 0.87 & $<0.05$ & 0.87 & & & & & $<0.001$ & 0.99 & $\mathrm{~N}$ & & & \\
\hline $\mathrm{pCA}$ & $<0.05$ & 0.95 & & & $<0.05$ & 0.87 & $<0.05$ & 0.87 & & & & & $<0.001$ & 0.99 & $\mathrm{~N}$ & & & \\
\hline TA & $<0.05$ & 0.88 & & & N & & & & & & & & $<0.01$ & 0.97 & $\mathrm{~N}$ & & & \\
\hline C & $<0.05$ & 0.95 & & & $<0.05$ & 0.83 & $<0.05$ & 0.87 & & & & & $<0.001$ & 0.99 & $\mathrm{~N}$ & & & \\
\hline C3G & $<0.05$ & 0.95 & & & $<0.05$ & 0.87 & $<0.05$ & 0.87 & & & & & $<0.001$ & 0.99 & $\mathrm{~N}$ & & & \\
\hline C3R & $<0.05$ & 0.95 & & & $<0.05$ & 0.87 & $<0.05$ & 0.87 & & & & & $<0.001$ & 0.99 & $\mathrm{~N}$ & & & \\
\hline $\mathrm{D}$ & $<0.05$ & 0.95 & & & $<0.05$ & 0.87 & $<0.05$ & 0.87 & & & & & $<0.001$ & 0.99 & $\mathrm{~N}$ & & & \\
\hline P & $<0.05$ & 0.86 & & & $<0.05$ & 0.81 & & & & & & & $<0.01$ & 0.97 & $\mathrm{~N}$ & & & \\
\hline TBARS & $<0.05$ & 0.87 & & & & & & & & & & & & & $\mathrm{~N}$ & & & \\
\hline PCG & $<0.05$ & 0.85 & & & $\Gamma$ & & & & & & & & & & $\mathrm{N}$ & & & \\
\hline
\end{tabular}

TBARS (thiobarbituric acid-reactive substances) and protein carbonyl group level in liver for the studied rats after two weeks of experiment. TPA—total phenolic acids (mg/kg body weight/d), CA—caffeic acid (mg/kg body weight/d), FA—ferrulic acid (mg/kg body weight/d), HBA-hydroxybenzoic acid (mg/kg body weight/d), SA-sinapic acid (mg/kg body weight/d), pCA—p-coumaric acid (mg/kg body weight/d), TA—-total anthocyanin (mg/kg body weight/d), C—cyanidin (mg/kg body weight/d), C3G—cyanidin 3-glucoside (mg/kg body weight/d), C3R—cyanidin 3-rutinoside ( $\mathrm{mg} / \mathrm{kg}$ body weight/d), D—delphinidin ( $\mathrm{mg} / \mathrm{kg}$ body weight/d), P—pelargonidin (mg/kg body weight/d), TBARS—-thiobarbituric acid-reactive substances level ( $\mu \mathrm{mol} / \mathrm{mg}$ protein), PCG-protein carbonyl group level $(\mathrm{nmol} / \mathrm{mL})$, and NS- nonsignificant statistically. 
The analysis of correlation between red wine intake, phenolic acids intake, anthocyanins intake, ethanol intake, TBARS level in liver, and protein carbonyl group level in liver for the studied rats after two weeks of experiment are presented in Table 4. It was stated that intake of the components of red wine were highly correlated with TBARS $(\mathrm{R}>0.80 ; p<0.05)$ for ethanol, total phenolic acids, caffeic acid, ferrulic acid, hydroxybenzoic acid, sinapic acid, p-coumaric acid, total anthocyanins, cyanidin, cyanidin 3-glucoside, cyanidin 3-rutinoside, delphinidin, and pelargonidin. A positive correlation was found also between red wine intake and TBARS level $(\mathrm{R}=0.87 ; p=0.023)$ and protein carbonyl group level in liver of rats $(\mathrm{R}>0.80 ; p<0.05)$. At the same time, there was a correlation between TBARS level and protein carbonyl group level $(\mathrm{R}=0.92 ; p=0.008)$, but no correlation between phenolic acids, anthocyanins, or ethanol intake and protein carbonyl group level. Moreover, a positive correlation was observed between ethanol intake and caffeic acid intake $(\mathrm{R}=1.00 ; p=0.000)$, ferrulic acid intake $(\mathrm{R}=1.00 ; p=0.000)$, hydroxybenzoic acid intake $(\mathrm{R}=1.00 ; p=0.000)$, sinapic acid intake $(\mathrm{R}=1.00 ; p=0.000)$, p-coumaric acid intake $(\mathrm{R}=1.00 ; p=0.000)$, total anthocyanins intake $(\mathrm{R}=0.98 ; p=0.001)$, cyanidin intake $(\mathrm{R}=1.00 ; p=0.000)$, cyanidin 3 -glucoside intake $(\mathrm{R}=1.00$; $p=0.000)$, cyanidin 3-rutinoside intake $(\mathrm{R}=1.00 ; p=0.000)$, delphinidin intake $(\mathrm{R}=0.95 ; p=0.003)$, and pelargonidin intake $(\mathrm{R}=0.97 ; p=0.001)$.

The analysis of correlation between red wine intake, phenolic acids intake, anthocyanins intake, and ethanol intake for the studied rats after four weeks of experiment are presented in Table 4. It was stated that intake of the components of red wine was neither correlated with TBARS, nor with protein carbonyl group level. Moreover, a positive correlation was observed between ethanol intake and total anthocyanins intake $(\mathrm{R}=0.87 ; p=0.011)$, cyanidin 3-glucoside intake $(\mathrm{R}=1.00 ; p=0.000)$, and pelargonidin intake $(\mathrm{R}=0.87 ; p=0.023)$.

The analysis of correlation between red wine intake, phenolic acids intake, anthocyanins intake, and ethanol intake for the studied rats after six weeks of experiment are presented in Table 4. It was stated that intake of the components of red wine was neither correlated with TBARS, nor with protein carbonyl group level. Moreover, a positive correlation was observed between ethanol intake and total phenolic acids intake $(\mathrm{R}=1.00 ; p=0.000)$, $\mathrm{p}$-coumaric acid intake $(\mathrm{R}=1.00 ; p=0.000)$ and hydroxybenzoic acid intake $(R=1.00 ; p=0.000)$, total anthocyanins intake $(R=0.99 ; p=0.000)$, pelargonidin intake $(\mathrm{R}=0.99 ; p=0.000)$.

\section{Discussion}

Oxidative stress is defined as the disturbance in balance between the production of reactive oxygen species (ROS) in cells or tissues and the possibility to dispose them [47]. ROS are by-products of cell metabolic activity, but their production may be enhanced by UV radiation, pollutants, drugs, cigarette smoke, and ethanol [48]. It is unclear whether oxidative stress and its associated mechanisms in adolescents differ from those in adults, but it should be noted that the period of maturation is highly sensitive for all the changes [49]. The data published thus far indicate mainly the association between oxidative stress in adolescents and pathogenesis of various diseases and disorders such as anxiety disorders [50], type 2 diabetes, obesity [51] and hypertension [52]. It results from the fact that ROS are essential for normal cell function; however, they mediate pathological changes in the brain, the kidney and blood vessels that contribute to the genesis of indicated diseases and disorders, while for hypertension, there is also emerging evidence that ROS contribute to immune activation [53]. In healthy adolescents, it is also noted that after intense physical activity, oxidative stress is increased, but it is unknown whether this increase is just adaptation to physical activity or a marker of oxidative damage $[54,55]$.

In the present study, a positive correlation was observed between intake of red wine or chosen polyphenols and protein carbonyl groups in the liver of growing male rats after two weeks of exposure, as a parameter of oxidative stress. In other rat model studies, while ethanol was administered alone (not as a component of a red wine), a higher level of protein carbonyl groups was observed than that in the control group [56]. Increased protein oxidation due to ethanol exposure may 
contribute to disturbed mitochondrial functions, which is commonly observed after prolonged alcohol consumption, while protein oxidation is a consequence of ROS generation during metabolic ethanol transformation [57]. However, Gris et al. [58] showed that after red wine consumption for 30 days, the level of protein carbonyl groups was decreased in the liver of adult mice. Similarly, Auberval et al. [59] proved that high-fat diet supplemented with red wine polyphenols caused a significant decrease in protein carbonyl groups and lipid peroxide levels in blood. Hence, it seems that red wine polyphenols may have a positive effect and reduce the negative consequences of ethanol consumption for protein oxidation. However, this was not observed in the growing rats in the present study. Lack of this influence in our study may have resulted from too low alcohol intake, being one of the major obstacles in animal model studies of alcohol consumption, as rodents typically do not self-administer alcohol in sufficient amounts to produce signs of intoxication, and even under circumstances when access is unlimited, they rarely consume alcohol in a manner that results in significant elevation in blood alcohol levels above legal limits [60]. The other possible explanation of the lack of the expected influence in the presented study may be associated with any adaptive, compensatory, or defense mechanisms resulting from alcohol consumption, protecting against ethanol-induced damage [61,62], even one that may be still unknown.

The TBARS level is one of the most important oxidative stress parameters that corresponds to the level of lipid oxidation. In the present study, a positive correlation was observed between ethanol consumption in the form of red wine and liver TBARS level in rats after two weeks of exposure. At the same time, Patere et al. [63] noted higher TBARS level in the liver of adult male rats receiving ethanol at a concentration of $10-30 \%$ for 30 days when compared with the control group. Similarly, Reddy et al. [56] showed that in the liver of adult male rats receiving $5 \mathrm{~g}$ of ethanol per $\mathrm{kg}$ of body weight at the concentration of $20 \%$ for 60 days, significantly higher TBARS level was observed than that found in the control group. This results from the fact that ethanol intake causes oxidative stress mainly due to increased production of oxygen free radicals and reduced antioxidant level in cells [64]. Fernandes et al. [65] revealed also that recurring episodes of alcohol intoxication in the period of maturation enhance liver lipid peroxidation process in growing female rats.

The present study revealed a positive association between red wine intake as well as intake of phenolic acids or anthocyanins and the TBARS level in the liver of growing male rats. To date, there is not enough studies on the influence of specific polyphenols of red wine on the oxidative stress parameters in the liver in growing organisms to be able to explain the results observed in the presented own study. Several studies conducted in humans and laboratory animals indicate the positive action of specific phenolic acids and anthocyanins on oxidative stress parameters, especially on lipid peroxidation. Duchnowicz et al. [66] noted that cyanidin 3-glucoside, ferulic acid, and p-coumaric acid significantly reduced lipid peroxidation in erythrocytes of patients with hypercholesterolemia; hence, it was concluded that these compounds are characterized by important antioxidative properties. Similarly, Balasubashini et al. [67] showed normalization of the TBARS level in the liver of diabetic mice after 45 days of oral supplementation of ferulic acid. Shen et al. [68] also revealed that p-coumaric acid is an important antioxidant that increases total antioxidant capacity and reduces lipid peroxidation in the liver of hyperlipidemic mice. At the same time, Zych et al. [69] noted a positive effect of sinapic acid on oxidative stress in the heart tissues of diabetic rats, while Yang et al. [70] revealed that sinapic acid applied in case of high-fat diet reduced ROS and malondialdehyde levels in the colon, while increasing the total antioxidant capacity in the liver of rats. Lafay et al. [71] also observed reduced liver TBARS level in rats receiving high doses of iron and caffeic acid for four weeks, and the authors emphasized its high bioavailability. Similarly, Montlahuc et al. [72] observed a negative association between hydroxybenzoic acid intake and TBARS blood level. Furthermore, Tsuda et al. [73] proved that cyanidin 3-glucoside was a powerful antioxidant and reduced oxidative damage in rat liver. From the abovementioned studies, it could be summarized that various phenolic acids or anthocyanins reduce lipid oxidation, which results from oxidative stress, in various tissues. 
Some other studies have assessed the influence of red wine and its polyphenols on oxidative stress parameters. Estruch et al. [74] revealed that in a group of men consuming moderate amount of red wine for 28 days, there was a significantly lower level of malondialdehyde-a marker of lipid peroxidation - than in those consuming gin; this finding was attributed to the influence of red wine polyphenols. Similarly, Gorinstein et al. [75] observed reduced level of lipid peroxidation products in blood of adult rats after four weeks of consumption of a diet supplemented with red wine solution or lyophilisate. However, the authors did not reveal any differences between the studied groups receiving red wine solution and lyophilisate, which was thought to be associated with a low concentration of ethanol and a high content of polyphenols received by both groups [75].

Pazzini et al. [76] and Montilla et al. [77] demonstrated that red wine may prevent hyperglycemia-induced lipid peroxidation, but the effect was observed only for low doses of red wine. This may indicate that consumption of low amounts of red wine is associated with a positive effect of polyphenols, but consumption of excessive amounts of alcohol may lead to the inability of polyphenols to neutralize the negative effect of ethanol itself. Schrieks et al. [78] conducted a study in a group of young men consuming red wine for four weeks; they observed significantly higher level of lipid oxidative damage marker in the red wine group than in the group consuming alcohol-free red wine. This confirms that polyphenols may be unable to neutralize the effect of ethanol. It may be possible that in the present study, the association between the intake of red wine or chosen polyphenols and TBARS level indicates the lack of possibility to neutralize the effect of ethanol in the applied conditions of the experiment. Moreover, it is also possible that during this specific period of maturation, lipid oxidation in the liver is enhanced due to intensive biological processes in the body. Metabolic transformation of polyphenols occurs mainly in the liver [79], but it remains unclear whether growing organisms have the same characteristics for metabolizing alcohol as adult organisms, as this aspect has not been studied to date. It is possible that in a growing organism, there is an action of both ethanol and polyphenols, which enhances oxidative stress in the liver. However, the associations observed in the group after two weeks of wine consumption were not observed after four and six weeks of wine consumption; this may be attributed to some mechanisms of adaptive changes to adjust to the conditions of constant exposure to ethanol and polyphenols from red wine. The indicated possibility of adaptation is presently a hypothesis, but it may be confirmed by the results observed by Martins et al. [80], as they noted that exposure to high resveratrol doses for a short time caused a significant increase in TBARS level, but no such effect was observed after longer exposure. Further studies are necessary to confirm the potential adaptation of a growing organism to red wine-induced oxidative processes in the liver.

The mechanism of action of polyphenols is associated with their ability to eliminate ROS, chelate metals, and influence the activity of enzymes, cell signal transduction pathways, and gene expression [81]. However, it must be emphasized that natural antioxidants may also act as a pro-oxidative agent by generating free radicals and causing DNA damage and mutagenesis [7]. Low-molecular-weight polyphenols such as gallic acid and quercetin are subjected to oxidation processes, and it is proven that they may exhibit pro-oxidative activity [82]; thus, such effect may also be assumed for other low-molecular-weight polyphenols studied in the present research, which may explain the observed results.

In the present study, red wine was analyzed for the content of only chosen polyphenols, while some other polyphenols were not considered. Among these excluded ones, there was resveratrol, being characterised by general anti-inflammatory, anticancer, cardioprotective, neuroprotective, anxiolytic, and phytoestrogenic effects [83], and according to recent reports, also influencing microbiota [84]. For a long time, resveratrol was supposed to be a polyphenol responsible for the beneficial effect of red wine, but recently, this opinion is questioned [85]. However, it must be mentioned here, that the effect of wine may be associated with the fact that phenolic compounds, as well as resultant total antioxidant capacity, but also volatile components of red wines may result from the region and its characteristics, including soil type, terrain characteristics, and climate conditions [86]. 
Xiang et al. [87] observed that the most abundant polyphenol in red wine was caffeic acid and the highest activity against free radicals was observed for gallic acid, while the contribution of resveratrol to the total antioxidative activity of red wine was lower than that of other polyphenols. On the basis of the obtained results, it was suggested that resveratrol may not be significant for the heath-promoting properties of red wine. At the same time, Cavallini et al. [88] proved that resveratrol requires the presence of other polyphenols to exert its optimum antioxidative activity. It is also emphasized that resveratrol has low bioavailability and possible side effects [83], including pro-oxidative and cytotoxic effects, depending on the dose and time of exposure [80]. Considering the fact that some polyphenols, including resveratrol, were not studied in the present research, it would be valuable to include them in further studies, as it is necessary to verify the obtained results because they suggest an important association between polyphenols of red wine and oxidative stress parameters in growing organisms.

The present study revealed statistically significant influence of red wine intake and intake of phenolic acids (hydroxybenzoic acid, caffeic acid, p-coumaric acid, ferulic acid, and sinapic acid) and anthocyanins (cyanidin, cyanidin 3-glucoside, cyanidin 3-rutinoside, delphinidin, and pelargonidin) on TBARS and protein carbonyl group levels, but the influence was observed only for a period of two weeks. The obtained results may suggest pro-oxidative effect of both ethanol and polyphenols on the liver of growing male rats. Moreover, after a period of four and six weeks, there was no influence on TBARS and protein carbonyl group levels; thus, it can be hypothesized that prolonged exposure of ethanol and polyphenols triggers an adaptive mechanism in growing organisms.

In spite of the fact that the conducted study did not allow to indicate which compounds of red wine were responsible for the observed effect, some important contributions of the presented study should be indicated. The most important observation is associated with the differences for the periods of two, four and six weeks. Moreover, as so far there were only some studies for growing organisms, the possibility of adaptive defense of the young organisms is also a novel observation. As a result, further studies are needed to confirm the mechanism of the pro-oxidative effect of polyphenols present in red wine on the liver of growing organisms.

In spite of the fact that the conducted study revealed a novel interesting observations, some limitations of the study must be listed. The most important issue is associated with the fact that the study was conducted in animal model, so transferring the observations into population is straitened. The other significant limitation is associated with the scope of the study-as only TBARS and protein carbonyl groups were included for the analysis, and some other factors also being markers of oxidative stress were not planned to be included. In the previous own study, it was indicated that alcohol consumption may have influenced hepatic antioxidant defense, while the catalase (CAT), superoxide dismutase (SOD), glutathione peroxidase, transferase (GST), reductase activities, total antioxidant status, and glutathione level (GSH) were analyzed [39]. However, to the conducted study, neither indicated parameters, nor the other factors (e.g., trolox equivalent antioxidant capacity (TEAC), cytochrome P450), were planned to be included. Similarly, in the future studies also other polyphenols should be included, such as quercetin and epicatechin, being among the major polyphenolic compounds of red wine [89].

The other important limitation results from a sample size which was sufficient for animal model study, but requires to be reproduced in a larger studies and also in a different models (including experiments for different red wines). The other issue is associated with the applied research methodology and tissue preparation, as some recent studies indicate that not only mild to moderate hypothermia should be applied, but also perfusion should be included to maintain hepatic viability and reduce oxidative stress which may influence TBARS results [90-92] and it is applied in some studies [93]. However, in a number of other studies, such perfusion is not applied and liver is proceeded immediately and in hypothermia only, to reduce oxidative stress and resultant changes [94-96] and such approach was chosen also for the presented study. As the tissue samples from all the studied groups were proceeded in an identical way, even if applied methodology have affected TBARS results, the influence was similar in all the groups and for between-group comparisons the influence may be 
negligible. However, in the future, similar analysis, but in the model with perfusion applied, should be also conducted.

\section{Conclusions}

The obtained results may suggest pro-oxidative effect of both ethanol and polyphenols for the liver of the growing male rats. At the same time, for period of four and six weeks, no influence on TBARS and protein carbonyl groups level was observed, which may allow to suppose adaptive mechanism of the growing organism while the ethanol and polyphenols exposition is prolonged. Further studies are required to confirm the mechanism of the pro-oxidative effect of polyphenols contained in red wine for the liver of growing organism.

Author Contributions: Conceptualization, A.K., M.O., and J.G.-O.; methodology, M.O. and J.G.-O.; formal analysis, A.K. and D.G.; investigation, A.K. and M.O.; writing-original draft preparation, A.K. and D.G.; and writing-review and editing, A.K., D.G., M.O., and J.G.-O. All authors have read and agreed to the published version of the manuscript.

Funding: The Polish Ministry of Science and Higher Education (research grant No. N N 312-158334) financed this experiment and the Polish Ministry of Science and Higher Education with the faculty of Human Nutrition, Warsaw University of Life Sciences (WULS), financed this scientific research.

Acknowledgments: We would like to acknowledge Agnieszka Malik from Department of Biotechnology, Microbiology, and Human Nutrition, Faculty of Food Science and Biotechnology, University of Life Sciences in Lublin, Poland; and Ewelina Hallmann from Department of Functional and Organic Food, Institute of Human Nutrition Sciences, Warsaw University of Life Sciences (SGGW-WULS), Poland, for their help in carrying out HPLC analysis of phenolic acids and anthocyanins (A.M.), and total phenolic acids (E.H.).

Conflicts of Interest: The authors declare no conflict of interest.

\section{References}

1. Spear, L.P. Adolescent alcohol exposure: Are there separable vulnerable periods within adolescence? Physiol. Behav. 2015, 148, 122-130. [CrossRef]

2. Green, K.M.; Doherty, E.E.; Zebrak, K.A.; Ensminger, M.E. Association between adolescent drinking and adult violence: Evidence from a longitudinal study of Urban African Americans. J. Stud. Alcohol Drugs 2011, 72, 701-710. [CrossRef]

3. Latvala, A.; Rose, R.J.; Pulkkinen, L.; Dick, D.M.; Korhonen, T.; Kaprio, J. Drinking, smoking, and educational achievement: Cross-lagged associations from adolescence to adulthood. Drug Alcohol Depend. 2014, 137, 106-113. [CrossRef]

4. Marshall, E.J. Adolescent alcohol use: Risks and consequences. Alcohol Alcohol. 2014, 49, 160-164. [CrossRef]

5. Squeglia, L.M.; Jacobus, J.; Tapert, S.F. The effect of alcohol use on human adolescent brain structures and systems. Handb. Clin. Neurol. 2014, 125, 501-510. [CrossRef]

6. Spear, L.P. Effects of adolescent alcohol consumption on the brain and behaviour. Nat. Rev. Neurosci. 2018, 19, 197-214. [CrossRef]

7. Rosa, R.C.; Rodrigues, W.F.; Miguel, C.B.; Cardoso, F.A.G.; Espindula, A.P.; Oliveira, C.J.F.; Volpon, J.B. Chronic consumption of alcohol adversely affects the bone of young rats. Acta Ortop. Bras. 2019, 27, 321-324. [CrossRef]

8. Block, G.D.; Yamamoto, M.E.; Mallick, A.; Styche, A.J. Effects on pubertal hormones by ethanol abuse in adolescents. Alcohol Clin. Exp. Res. 1993, 17, 505.

9. Clark, D.B.; Lynch, K.G.; Donovan, J.E.; Block, G.D. Health problems in adolescents with alcohol use disorders: Self-report, liver injury, and physical examination findings and correlates. Alcohol. Clin. Exp. Res. 2001, 25, 1350-1359. [CrossRef]

10. Petit, G.; Kornreich, C.; Verbanck, P.; Cimochowska, A.; Campanella, S. Why is adolescence a key period of alcohol initiation and who is prone to develop long-term problem use?: A review of current available data. Socioaffect. Neurosci. Psychol. 2013, 3, 21890. [CrossRef]

11. The ESPAD Group. ESPAD Report 2015. Results from the European School Survey Project on Alcohol and Other Drugs; Publications Office of the European Union: Luxembourg, 2016.

12. Adger, H.; Saha, S. Alcohol use disorders in adolescents. Pediatr. Rev. 2013, 34, 103-114. [CrossRef] 
13. Leri, M.; Scuto, M.; Ontario, M.L.; Calabrese, V.; Calabrese, V.; Bucciantini, M.; Stefani, M. Calabrese Healthy effects of plant polyphenols: Molecular mechanisms. Int. J. Mol. Sci. 2020, 21, 1250. [CrossRef]

14. Bazal, P.; Gea, A.; Martínez-González, M.; Salas-Salvadó, J.; Asensio, E.; Muñoz-Bravo, C.; Fiol, M.; Muñoz, M.-A.; Lapetra, J.; Serra-Majem, L.; et al. Mediterranean alcohol-drinking pattern, low to moderate alcohol intake and risk of atrial fibrillation in the PREDIMED study. Nutr. Metab. Cardiovasc. Dis. 2019, 29, 676-683. [CrossRef]

15. Popova, S.; Rehm, J.; Patra, J.; Zatonski, W. Comparing alcohol consumption in central and eastern Europe to other European countries. Alcohol Alcohol. 2007, 42, 465-473. [CrossRef]

16. Sudhinaraset, M.; Wigglesworth, C.; Takeuchi, D.T. Social and cultural contexts of alcohol use. Alcohol Res. Curr. Rev. 2016, 38, 35-45.

17. WHO. Alcohol in the European Union. Consumption, Harm and Policy Approaches; Anderson, P., Møllerand, L., Galea, G., Eds.; WHO Regional Office for Europe: Copenhagen, Denmark, 2012.

18. Sieri, S.; Agudo, A.; Kesse-Guyot, E.; Klipstein-Grobusch, K.; San-José, B.; Welch, A.; Krogh, V.; Luben, R.N.; Allen, N.; Overvad, K.; et al. Patterns of alcohol consumption in 10 European countries participating in the European prospective investigation into cancer and nutrition (EPIC) project. Public Health Nutr. 2002, 5 , 1287-1296. [CrossRef]

19. Bräker, A.B.; Soellner, R. Alcohol drinking cultures of European adolescents. Eur. J. Public Health 2016, 26, 581-586. [CrossRef]

20. Salucci, S.; Burattini, S.; Giordano, F.M.; Lucarini, S.; Diamantini, G.; Falcieri, E. Further highlighting on the prevention of oxidative damage by polyphenol-rich wine extracts. J. Med. Food 2017, 20, 410-419. [CrossRef]

21. Fernandes, I.; Pérez-Gregorio, M.; Soares, S.; Mateus, N.; De Freitas, V. Wine flavonoids in health and disease prevention. Molecules 2017, 22, 292. [CrossRef]

22. Kammerer, D.; Claus, A.; Carle, R.; Schieber, A. Polyphenol screening of pomace from red and white grape varieties (Vitis viniferaL.) by HPLC-DAD-MS/MS. J. Agric. Food Chem. 2004, 52, 4360-4367. [CrossRef]

23. Quideau, S.; Deffieux, D.; Douat-Casassus, C.; Pouysegu, L. Plant polyphenols: Chemical properties, biological activities, and synthesis. Angew. Chem. Int. Ed. 2011, 17, 586-621. [CrossRef] [PubMed]

24. Champ, C.E.; Kundu-Champ, A. Maximizing polyphenol content to uncork the relationship between wine and cancer. Front. Nutr. 2019, 6, 44. [CrossRef] [PubMed]

25. Tanaka, T.; Iuchi, A.; Harada, H.; Hashimoto, S. Potential beneficial effects of wine flavonoids on allergic diseases. Diseases 2019, 7, 8. [CrossRef]

26. Eghbaliferiz, S.; Iranshahi, M. Prooxidant activity of polyphenols, flavonoids, anthocyanins and carotenoids: Updated review of mechanisms and catalyzing metals. Phytother. Res. 2016, 30, 1379-1391. [CrossRef]

27. Pavlidou, E.; Mantzorou, M.; Fasoulas, A.; Tryfonos, C.; Petridis, D.; Giaginis, C. Wine: An aspiring agent in promoting longevity and preventing chronic diseases. Diseases 2018, 6, 73. [CrossRef]

28. Osna, N.A.; Donohue, T.M.; Kharbanda, K.K. Alcoholic liver disease: Pathogenesis and current management. Alcohol Res. 2017, 38, 147-161.

29. Beery, A.K.; Holmes, M.M.; Lee, W.; Curley, J.P. Stress in groups: Lessons from non-traditional rodent species and housing models. Neurosci. Biobehav. Rev. 2020, 113, 354-372. [CrossRef]

30. Becker, H.C.; Lopez, M.F.; Doremus-Fitzwater, T.L. Effects of stress on alcohol drinking: A review of animal studies. Psychopharmacology 2011, 218, 131-156. [CrossRef]

31. Ramirez, H.E.; Esperon, L.; Peris, J. Effects of an enrichment device on voluntary alcohol consumption on single-housed rats. J. Am. Assoc. Lab. Anim. Sci. 2008, 47, 24-29.

32. Holgate, J.Y.; Shariff, M.; Mu, E.W.H.; Bartlett, S.E. A rat drinking in the dark model for studying ethanol and sucrose consumption. Front. Behav. Neurosci. 2017, 11, 29. [CrossRef]

33. Li, J.; Chen, P.; Han, X.; Zuo, W.; Mei, Q.; Bian, E.Y.; Umeugo, J.; Ye, J.H. Differences between male and female rats in alcohol drinking, negative affects and neuronal activity after acute and prolonged abstinence. Int. J. Physiol Pathophysiol. Pharmacol. 2019, 11, 163-176. [PubMed]

34. Priddy, B.M.; Carmack, S.A.; Thomas, L.C.; Vendruscolo, J.C.; Koob, G.F.; Vendruscolo, L.F. Sex, strain, and estrous cycle influences on alcohol drinking in rats. Pharmacol. Biochem. Behav. 2017, 152, 61-67. [CrossRef] [PubMed]

35. Spoelder, M.; Dourojeanni, J.P.F.; De Git, K.C.G.; Baars, A.M.; Lesscher, H.M.B.; Vanderschuren, L.J. Individual differences in voluntary alcohol intake in rats: Relationship with impulsivity, decision making and Pavlovian conditioned approach. Psychopharmacology 2017, 234, 2177-2196. [CrossRef] 
36. Carnicella, S.; Ron, R.; Barak, S. Intermittent ethanol access schedule in rats as a preclinical model of alcohol abuse. Alcohol 2014, 48, 243-252. [CrossRef] [PubMed]

37. Krohn, T.C.; Sørensen, D.B.; Ottesen, J.L.; Hansen, A.K. The effects of individual housing on mice and rats: A review. Anim. Welf. 2006, 15, 343-352.

38. Kołota, A.; Głąska, D.; Oczkowski, M.; Gromadzka-Ostrowska, J. Oxidative stress parameters in the liver of growing male rats receiving various alcoholic beverages. Nutrients 2020, 12, 158. [CrossRef]

39. Kołota, A.; Głąbska, D.; Oczkowski, M.; Gromadzka-Ostrowska, J. Influence of alcohol consumption on body mass gain and liver antioxidant defense in adolescent growing male rats. Int. J. Environ. Res. Public Health 2019, 16, 2320. [CrossRef]

40. Chaloupka, F.J. The effects of price on alcohol use, abuse, and their consequences. In Reducing Underage Drinking: A Collective Responsibility; Bonnie, R.J., O'Connell, M.E., Eds.; National Academies Press: Washington, WA, USA, 2004.

41. Milat, A.M.; Mudnić, I.; Grković, I.; Ključević, N.; Grga, M.; Jerčić, I.; Jurić, D.; Ivanković, D.; Benzon, B.; Boban, M. Efects of white wine consumption on weight in rats: Do polyphenols matter? Oxid. Med. Cell. Longev. 2017, 2017, 8315803. [CrossRef]

42. Ohkawa, H.; Ohishi, N.; Yagi, K. Assay for lipid peroxides in animal tissues by thiobarbituric acid reaction. Anal. Biochem. 1979, 95, 351-358. [CrossRef]

43. Reznick, A.Z.; Packer, L. [38] Oxidative damage to proteins: Spectrophotometric method for carbonyl assay. Methods Enzymol. 1994, 233, 357-363. [CrossRef]

44. Levine, R.L.; Williams, J.A.; Stadtman, E.P.; Shacter, E. Carbonyl assays for determination of oxidatively modified proteins. Methods Enzymol. 1994, 233, 346-357. [CrossRef] [PubMed]

45. Singleton, V.L.; Rossi, J.A. Colorimetry of total phenolics with phosphomolybdicphosphotungstic acid reagents. Am. J. Enol. Vitic. 1965, 16, 144-158.

46. Häkkinen, S.H.; Kärenlampi, S.O.; Heinonen, I.M.; Mykkänen, H.M.; Törrönen, A.R. HPLC method for screening of flavonoids and phenolic acids in berries. J. Sci. Food Agric. 1998, 77, 543-551. [CrossRef]

47. Pizzino, G.; Irrera, N.; Cucinotta, M.; Pallio, G.; Mannino, F.; Arcoraci, V.; Squadrito, F.; Altavilla, D.; Bitto, A. Oxidative stress: Harms and benefits for human health. Oxid. Med. Cell. Longev. 2017, 2017, 8416763. [CrossRef] [PubMed]

48. Bhattacharyya, A.; Chattopadhyay, R.; Mitra, S.; Crowe, S.E. Oxidative stress: An essential factor in the pathogenesis of gastrointestinal mucosal diseases. Physiol. Rev. 2014, 94, 329-354. [CrossRef]

49. Farello, G.; Altieri, C.; Cutini, M.; Pozzobon, G.; Verrotti, A. Review of the literature on current changes in the timing of pubertal development and the incomplete forms of early puberty. Front. Pediatr. 2019, 7, 147. [CrossRef]

50. Guney, E.; Ceylan, M.F.; Tektas, A.; Alisik, M.; Ergin, M.; Göker, Z.; Dinc, G.S.; Ozturk, O.; Korkmaz, A.; Eker, S. Oxidative stress in children and adolescents with anxiety disorders. J. Affect. Disord. 2014, 156, $62-66$. [CrossRef]

51. Tauman, R.; Shalitin, S.; Lavie, L. Oxidative stress in obese children and adolescents with and without type 2 diabetes mellitus is not associated with obstructive sleep apnea. Sleep Breath. 2019, 23, 117-123. [CrossRef]

52. Túri, S.; Friedman, A.; Bereczki, C.; Papp, F.; Kovács, J.; Karg, E.; Németh, I. Oxidative stress in juvenile essential hypertension. J. Hypertens. 2003, 21, 145-152. [CrossRef]

53. Loperena, R.; Harrison, D.G. Oxidative stress and hypertensive diseases. Med. Clin. N. Am. 2017, 101, 169-193. [CrossRef]

54. Nasca, M.M.; Zhang, R.; Super, D.M.; Hazen, S.L.; Hall, H.R. Increased oxidative stress in healthy children following an exercise program: A pilot study. J. Dev. Behav. Pediatr. 2010, 31, 386-392. [CrossRef] [PubMed]

55. Avloniti, A.; Chatzinikolaou, A.; Deli, C.K.; Vlachopoulos, D.; Gracia-Marco, L.; Leontsini, D.; Draganidis, D.; Jamurtas, A.Z.; Mastorakos, G.; Fatouros, I.G. Exercise-induced oxidative stress responses in the pediatric population. Antioxidants 2017, 17, 6. [CrossRef] [PubMed]

56. Reddy, V.D.; Padmavathi, P.; Hymavathi, R.; Maturu, P.; Varadacharyulu, N. Alcohol-induced oxidative stress in rat liver microsomes: Protective effect of Emblica officinalis. Pathophysiology 2014, 21, 153-159. [CrossRef] [PubMed]

57. Galicia-Moreno, M.; Gutiérrez-Reyes, G. Papel del estrés oxidativo en el desarrollo de la enfermedad hepática alcohólica. Rev. Gastroenterol. Mex. 2014, 79, 135-144. [CrossRef] [PubMed] 
58. Gris, E.; Mattivi, F.; Ferreira, E.; Vrhovsek, U.; Filho, D.; Pedrosa, R.; Bordignon-Luiz, M.T. Phenolic profile and effect of regular consumption of Brazilian red wines on in vivo antioxidant activity. J. Food Compos. Anal. 2013, 31, 31-40. [CrossRef]

59. Auberval, N.; Dal, S.; Maillard, E.; Bietiger, W.; Peronet, C.; Pinget, M.; Schini-Kerth, V.; Sigrist, S. Beneficial effects of a red wine polyphenol extract on high-fat diet-induced metabolic syndrome in rats. Eur. J. Nutr. 2016, 56, 1467-1475. [CrossRef]

60. Becker, H.C.; Ron, R. Animal models of excessive alcohol consumption: Recent advances and future challenges. Alcohol 2014, 48, 205-208. [CrossRef]

61. Hernández, J.A.; López-Sánchez, R.C.; Rendón-Ramírez, A. Lipids and oxidative stress associated with ethanol-induced neurological damage. Oxid. Med. Cell. Longev. 2016, 2016, 1543809. [CrossRef]

62. Ceni, E.; Mello, T.; Galli, A. Pathogenesis of alcoholic liver disease: Role of oxidative metabolism. World J. Gastroenterol. 2014, 20, 17756-17772. [CrossRef]

63. Majumdar, A.; Patere, S.; Saraf, M.N. Exacerbation of alcohol-induced oxidative stress in rats by polyunsaturated fatty acids and iron load. Indian J. Pharm. Sci. 2011, 73, 152-158. [CrossRef]

64. Dey, A.; Cederbaum, A.I. Alcohol and oxidative liver injury. Hepatology 2006, 43, S63-S74. [CrossRef] [PubMed]

65. Fernandes, L.M.P.; Lopes, K.S.; Santana, L.N.S.; Fontes-Júnior, E.A.; Ribeiro, C.H.M.A.; Silva, M.C.F.; Paraense, R.S.D.O.; Crespo-López, M.E.; Gomes, A.R.Q.; Lima, R.R.; et al. Repeated cycles of binge-like ethanol intake in adolescent female rats induce motor function impairment and oxidative damage in motor cortex and liver, but not in blood. Oxid. Med. Cell. Longev. 2018, 2018, 3467531. [CrossRef]

66. Duchnowicz, P.; Broncel, M.; Podsędek, A.; Koter, M. Hypolipidemic and antioxidant effects of hydroxycinnamic acids, quercetin, and cyanidin 3-glucoside in hypercholesterolemic erythrocytes (in vitro study). Eur. J. Nutr. 2011, 51, 435-443. [CrossRef] [PubMed]

67. Balasubashini, M.S.; Rukkumani, R.; Viswanathan, P.; Menon, V.P. Ferulic acid alleviates lipid peroxidation in diabetic rats. Phytother. Res. 2004, 18, 310-314. [CrossRef]

68. Shen, Y.; Song, X.; Li, L.; Sun, J.; Jaiswal, Y.; Huang, J.; Liu, C.; Yang, W.; Williams, L.; Zhang, H.; et al. Protective effects of $\mathrm{p}$-coumaric acid against oxidant and hyperlipidemia-an in vitro and in vivo evaluation. Biomed. Pharmacother. 2019, 111, 579-587. [CrossRef] [PubMed]

69. Zych, M.; Wojnar, W.; Borymski, S.; Szałabska, K.; Bramora, P.; Kaczmarczyk-Sedlak, I. Effect of rosmarinic acid and sinapic acid on oxidative stress parameters in the cardiac tissue and serum of type 2 diabetic female rats. Antioxidants 2019, 8, 579. [CrossRef] [PubMed]

70. Yang, C.; Deng, Q.; Xu, J.; Wang, X.; Hu, C.; Tang, H.; Huang, F. Sinapic acid and resveratrol alleviate oxidative stress with modulation of gut microbiota in high-fat diet-fed rats. Food Res. Int. 2019, 116, 1202-1211. [CrossRef]

71. Lafay, S.; Gueux, E.; Rayssiguier, Y.; Mazur, A.; Rémésy, C.; Scalbert, A. Caffeic acid inhibits oxidative stress and reduces hypercholesterolemia induced by iron overload in rats. Int. J. Vitam. Nutr. Res. 2005, 75, 119-125. [CrossRef]

72. Montlahuc, C.; Julia, C.; Touvier, M.; Fezeu, L.; Hercberg, S.; Galan, P.; Kesse-Guyot, E.; Chevret, S. Association between dietary polyphenols intake and an oxidative stress biomarker: Interest of multiple imputation for handling missing covariates and outcomes. BMC Nutr. 2016, 2, 71. [CrossRef]

73. Tsuda, T.; Horio, F.; Osawa, T. The role of anthocyanins as an antioxidant under oxidative stress in rats. BioFactors 2000, 13, 133-139. [CrossRef]

74. Estruch, R.; Sacanella, E.; Mota, F.; Chiva-Blanch, G.; Antúnez, E.; Casals, E.; Deulofeu, R.; Rotilio, D.; Andres-Lacueva, C.; Lamuela-Raventós, R.M. Moderate consumption of red wine, but not gin, decreases erythrocyte superoxide dismutase activity: A randomised cross-over trial. Nutr. Metab. Cardiovasc. Dis. 2009, 21, 46-53. [CrossRef] [PubMed]

75. Gorinstein, S.; Zemser, M.; Weisz, M.; Halevy, S.; Martín-Belloso, O.; Trakhtenberg, S. The influence of alcohol-containing and alcohol-free beverages on lipid levels and lipid peroxides in serum of rats. J. Nutr. Biochem. 1998, 9, 682-686. [CrossRef]

76. Pazzini, C.E.F.; Colpo, A.C.; Poetini, M.R.; Pires, C.F.; De Camargo, V.B.; Mendez, A.S.L.; Azevedo, M.L.; Soares, J.C.M.; Folmer, V. Effects of red wine tannat on oxidative stress induced by glucose and fructose in erythrocytes in vitro. Int. J. Med. Sci. 2015, 12, 478-486. [CrossRef] [PubMed] 
77. Montilla-López, P.; Barcos, M.; Muñoz, M.; Muñoz-Castañeda, J.R.; Bujalance, I.; Túnez, I. Protective effect of Montilla-Moriles appellation red wine on oxidative stress induced by streptozotocin in the rat. J. Nutr. Biochem. 2004, 15, 688-693. [CrossRef]

78. Schrieks, I.C.; Berg, R.V.D.; Sierksma, A.; Beulens, J.W.; Vaes, W.H.; Hendriks, H.F. Effect of red wine consumption on biomarkers of oxidative stress. Alcohol Alcohol. 2012, 48, 153-159. [CrossRef] [PubMed]

79. Zorraquín-Peña, I.; Esteban-Fernández, A.; De Llano, D.G.; Bartolomé, B.; Moreno-Arribas, M.V. Wine-derived phenolic metabolites in the digestive and brain function. Beverages 2019, 5, 7. [CrossRef]

80. Martins, L.A.M.M.; Coelho, B.P.; Behr, G.; Pettenuzzo, L.; De Souza, I.C.C.; Moreira, J.C.F.; Borojevic, R.; Gottfried, C.; Guma, F.C.R. Resveratrol induces pro-oxidant effects and time-dependent resistance to cytotoxicity in activated hepatic stellate cells. Cell Biophys. 2013, 68, 247-257. [CrossRef]

81. Soobrattee, M.; Neergheen, V.; Luximon-Ramma, A.; Aruoma, O.I.; Bahorun, T. Phenolics as potential antioxidant therapeutic agents: Mechanism and actions. Mutat. Res. 2005, 579, 200-213. [CrossRef]

82. Hagerman, A.E.; Riedl, K.M.; Jones, G.A.; Sovik, K.N.; Ritchard, N.T.; Hartzfeld, P.W.; Riechel, T.L. High molecular weight plant polyphenolics (tannins) as biological antioxidants. J. Agric. Food Chem. 1998, 46, 1887-1892. [CrossRef]

83. Salehi, B.; Mishra, A.P.; Nigam, M.; Sener, B.; Kılıç, M.; Sharifi-Rad, J.; Fokou, P.V.T.; Martins, N.; Sharifi-Rad, J. Resveratrol: A double-edged sword in health benefits. Biomedicines 2018, 6, 91. [CrossRef]

84. Man, A.W.; Li, H.; Xia, N. Resveratrol and the interaction between gut microbiota and arterial remodelling. Nutrients 2020, 12, 119. [CrossRef]

85. Weiskirchen, S.; Weiskirchen, R. Resveratrol: How much wine do you have to drink to stay healthy? Adv. Nutr. 2016, 7, 706-718. [CrossRef] [PubMed]

86. Jiang, B.; Sun, Z.Y. Phenolic compounds, total antioxidant capacity and volatile components of Cabernet Sauvignon red wines from five different wine-producing regions in China. Food Sci. Technol. 2018, 39, 735-746. [CrossRef]

87. Xiang, L.; Xiao, L.; Wang, Y.; Li, H.; Huang, Z.; He, X. Health benefits of wine: Don't expect resveratrol too much. Food Chem. 2014, 156, 258-263. [CrossRef] [PubMed]

88. Cavallini, G.; Straniero, S.; Donati, A.; Bergamini, E. Resveratrol requires red wine polyphenols for optimum antioxidant activity. J. Nutr. Health Aging 2016, 20, 540-545. [CrossRef]

89. Zenebe, W.; Pechánová, O.; Bernátová, I. Protective effects of red wine polyphenolic compounds on the cardiovascular system. Exp. Clin. Cardiol. 2001, 6, 153-158.

90. Carbonell, T.; Alva, N.; Sánchez-Nuño, S.; Dewey, S.; Gomes, A.V. Subnormothermic perfusion in the isolated rat liver preserves the antioxidant glutathione and enhances the function of the ubiquitin proteasome system. Oxid. Med. Cell. Longev. 2016, 2016, 9324692. [CrossRef]

91. Alva, N.; Bardallo, R.G.; Basanta, D.; Palomeque, J.; Carbonell, T. Preconditioning-like properties of short-term hypothermia in isolated perfused rat Liver (IPRL) system. Int. J. Mol. Sci. 2018, 19, 1023. [CrossRef]

92. Bellini, M.I.; Yiu, J.; Nozdrin, M.; Papalois, V. The effect of preservation temperature on liver, kidney, and pancreas tissue ATP in animal and preclinical human models. J. Clin. Med. 2019, 8, 1421. [CrossRef]

93. Piotrowska-Kempisty, H.; Nowicki, M.; Jodynis-Liebert, J.; Kurpik, M.; Ewertowska, M.; Adamska, T.; Oszmiański, J.; Kujawska, M. Assessment of hepatoprotective effect of chokeberry juice in rats treated chronically with carbon tetrachloride. Molecules 2020, 25, 1268. [CrossRef]

94. Mohamadin, A.M.; Hammad, L.N.A.; El-Bab, M.F.; Gawad, H.S.A. Attenuation of oxidative stress in plasma and tissues of rats with experimentally induced hyperthyroidism by caffeic acid phenylethyl ester. Basic Clin. Pharmacol. Toxicol. 2006, 100, 84-90. [CrossRef] [PubMed]

95. Noeman, S.A.; Hamooda, H.E.; Baalash, A.A. Biochemical study of oxidative stress markers in the liver, kidney and heart of high fat diet induced obesity in rats. Diabetol. Metab. Syndr. 2011, 3, 17. [CrossRef] [PubMed]

96. Freitas, I.; Boncompagni, E.; Tarantola, E.; Gruppi, C.; Bertone, V.; Ferrigno, A.; Milanesi, G.; Vaccarone, R.; Tira, M.E.; Vairetti, M. In situevaluation of oxidative stress in rat fatty liver induced by a methionine- and choline-deficient diet. Oxid. Med. Cell. Longev. 2016, 2016, 9307064. [CrossRef]

(C) 2020 by the authors. Licensee MDPI, Basel, Switzerland. This article is an open access article distributed under the terms and conditions of the Creative Commons Attribution (CC BY) license (http://creativecommons.org/licenses/by/4.0/). 